\title{
A Case Report of Adrenocortical Carcinoma
}

\author{
Mika Ishikawa, Shoko Ikema, Masahiro Goto, Reiko Horikawa, Toshiaki Tanaka, Ayako Tanae, \\ Toshiro Honna and Kentaro Matsuoka \\ Divisions of Endocrinology and Metabolism (MI, SI, MG, RH, AT), Surgery (TH), Pathology (KM), National \\ Children's Hospital, Endocrine Research Loboratory, National Children's Medical Research Center (TT), Tokyo, \\ Japan
}

Key words: adrenocortical carcinoma, IGF-I, 21-hydroxylase deficiency

\section{Introduction}

Most adrenocortical tumors produce hormonally active substances. We report a case with virilyzing adrenocortical carcinoma and evaluated his growth pattern compared with those of untreated 21-hydroxylase deficiency patients.

\section{Case Report}

A 1-year 3-month old boy was referred to our hospital for complaints of facial acne, lowpitched voice and hirsutism. His height was 78.1 $\mathrm{cm}$ (mean) and weight was $12.2 \mathrm{~kg}(+2.0 \mathrm{SD})$. Blood pressure was normal. Penile enlargement and pubic hair (Tanner stage III) were also noted on physical examination.

The levels of adrenal androgens, especially testosterone, were high (Table 1). The diurnal rhythm of cortisol was absent. Serum cortisol and plasma ACTH were not responsive to CRH test. Serum cortisol, adrenal androgens and urinary $17-\mathrm{KS}$ were not suppressed by dexamethazone ( $1 \mathrm{mg} \times 2$ days and $4 \mathrm{mg} \times 2$ days). The level of IGF-I was high

Correspondence: Dr. Mika Ishikawa, Division of Endocrinology, National Children's Hospital, 3-35-31 Taishido, Setagaya-ku, Tokyo 154, Japan for his age ( $330 \mathrm{ng} / \mathrm{ml})$. The $\mathrm{GH}$ response to GRF test was normal. Bone age was 19 months (Greulich \& Pyle method). A right suprarenal mass was found by CT and ultrasound, and diagnosed as a right adrenal tumor. Right adrenalectomy was done. The tumor measured $2.5 \times 2.5 \times 2.5$ $\mathrm{cm}$ and weighed $9 \mathrm{~g}$. The pathological diagnosis was adrenocortical carcinoma. Steroid contents in the tumor are shown in Table 2.

After operation, serum androgen rapidly decreased to the normal level and the IGF-I level decreased to $160 \mathrm{ng} / \mathrm{ml}$ one month after removal of the adrenal tumor.

\section{Discussion}

The serum IGF-I level was very high before removal of the adrenal tumor. This increase may be induced by the sex hormones secreted from the adrenal tumor. It is not clear whether this is a direct effect of sex stcroid or mediated by an increase in $\mathrm{GH}$ secretion.

The growth spurt of this patient was smaller than those of untreated infants with 21-hydroxylase deficiency, although in the present case there was a much higher level of testosterone (Fig. 1). The results suggested that the tumor might begin to secrete adrenal androgens a few months before admission and hypercortisolism 
Table 1 Steroid profile in the peripheral blood

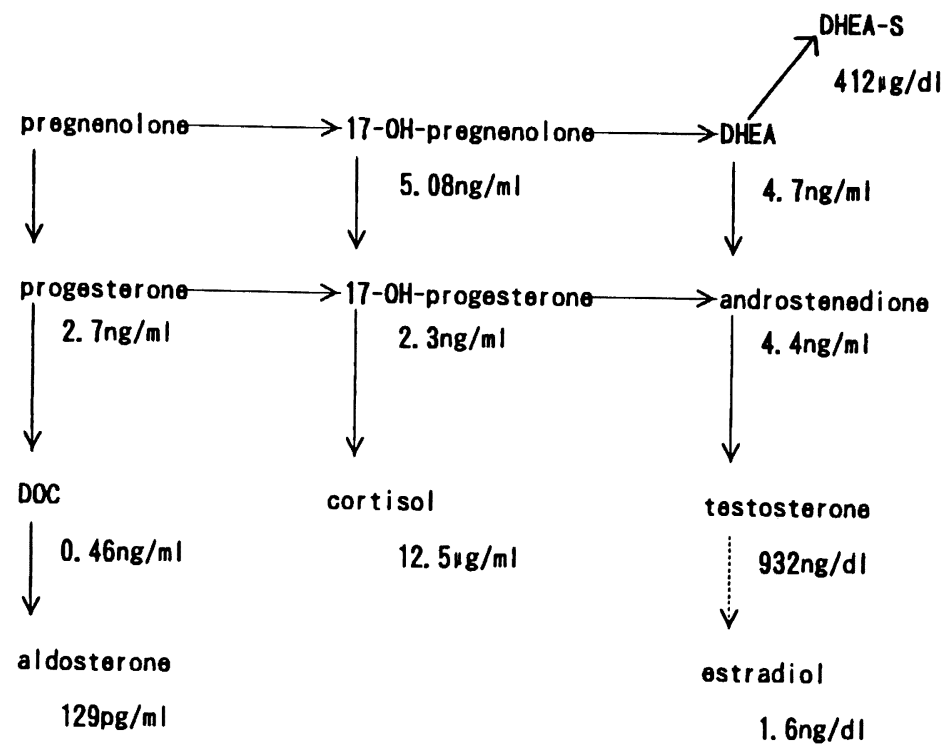

Table 2 Steroid content in the tumor tissue

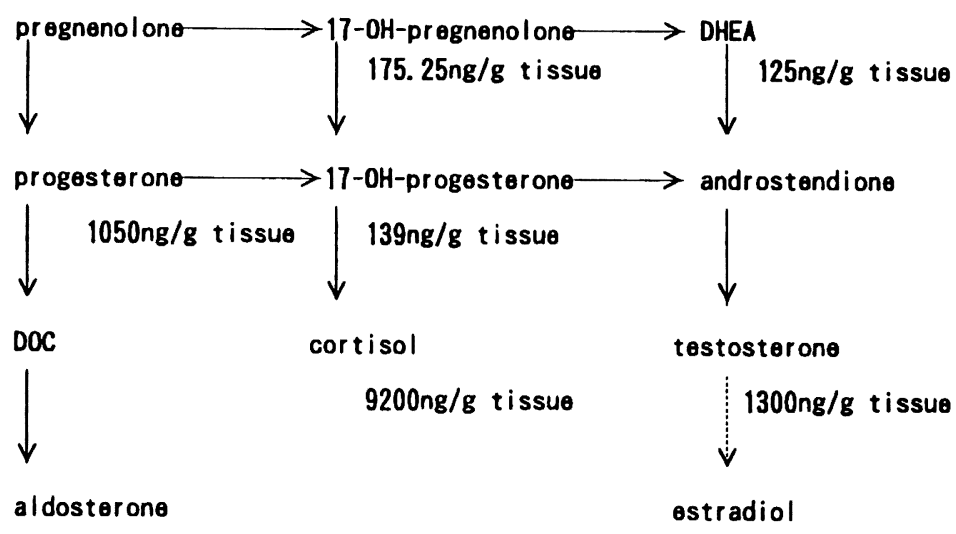

12. $5 \mathrm{ng} / \mathrm{g}$ tissue

223pg/g tissue

suppressed the effect of the sex steroid or IGF-I on bone growth.

\section{References}

1. Kasperlik-Zaluska AA, Migdalska B, Zgliczynski S, Makowska A. Adrenocortical Carcinoma. A clinical study and treatment results of 52 patients. Cancer 1995; 75: 2587-91.
2. Cuerda C, Estrada J, Marazuela M, Vincente A, Astigarraga B, Bernabeu I, et al. Anterior pituitary function in Cushing's syndrome: Study of 36 patients. Endocrinol Japon 1991; 38: 559-63.

3. Phillip DK, Robert JW, Orville CG. Virilyzing Adrenocortical tumors in childhood: Eight cases and a review of the literature. Pediatrics 1985; 76: $437-44$. 


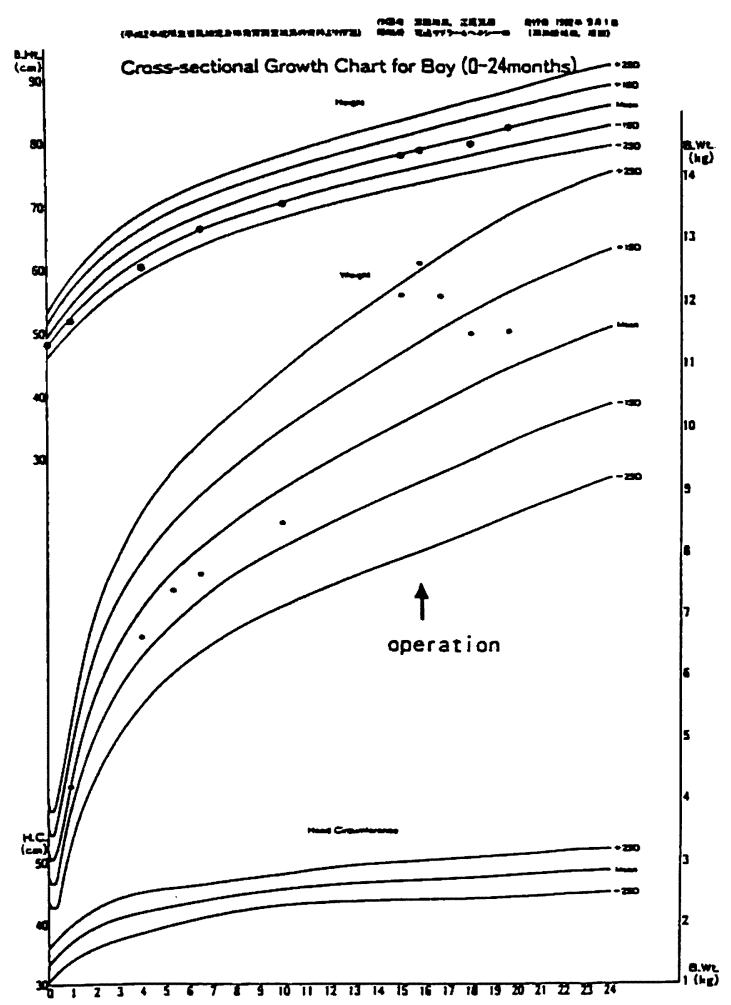

(a)

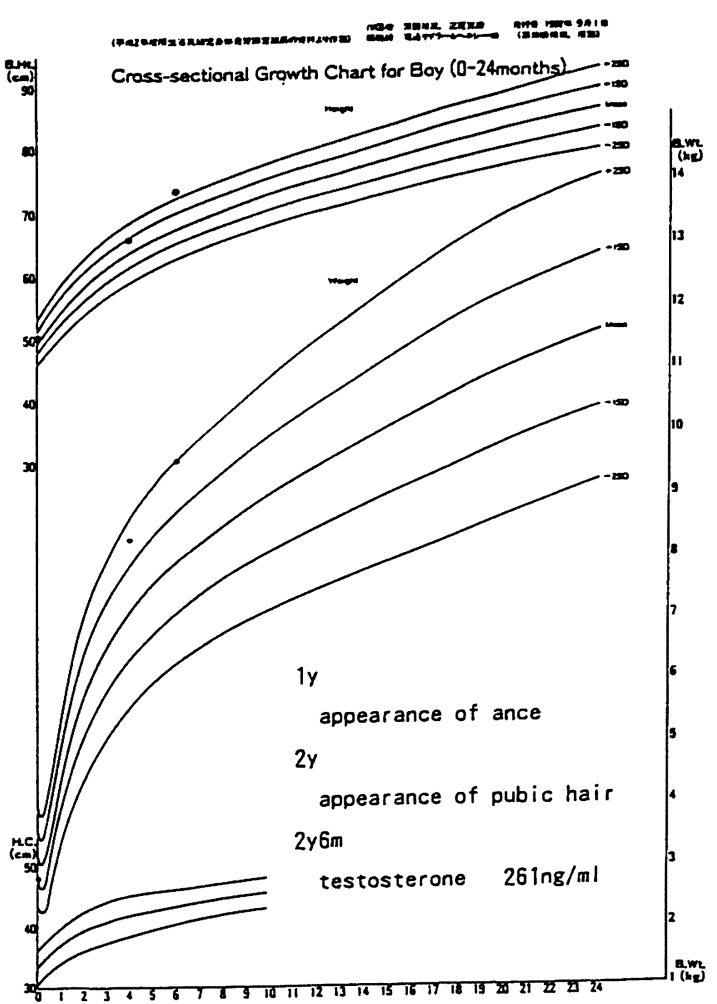

(b)

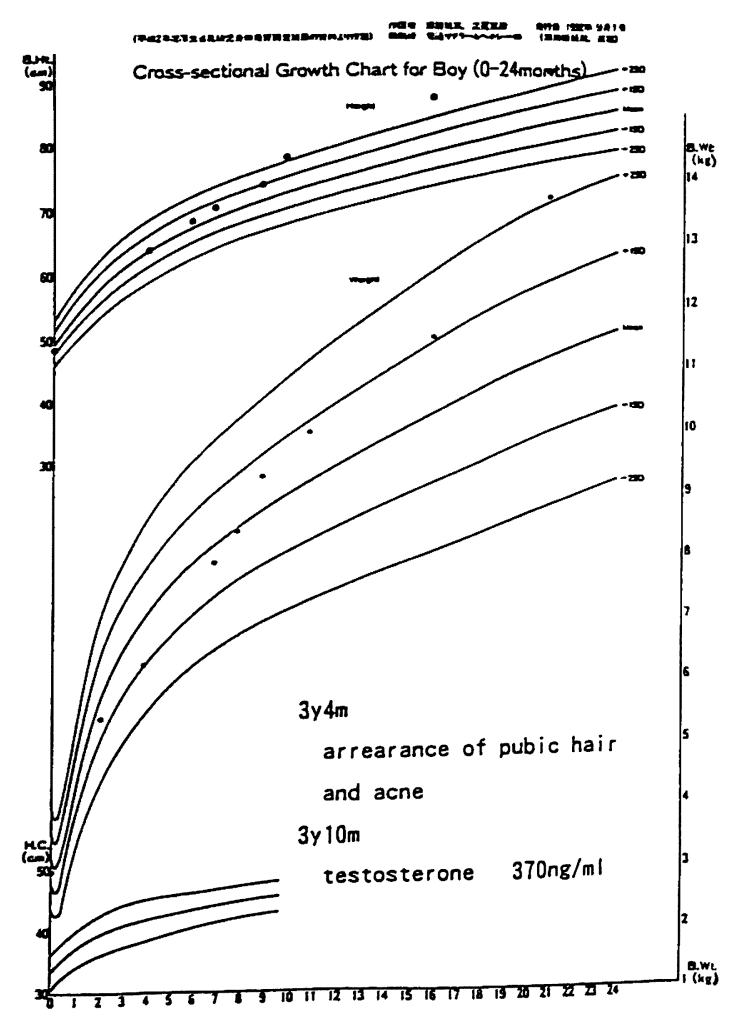

Fig. 1 Growth pattern of the present case (a) and male patients with 21hydroxylase deficiency $(b, c)$

(c) 